\title{
Derleme
}

Mersin Univ Saglık Bilim Derg 2019;12(3):542-552

doi:10.26559/mersinsbd.630237

\section{Yaşa bağlı gelişen bozukluklarda polifenoller ve hedefleri; mTOR sinyal ileti yolu}

\author{
Meryem Temiz Reşitoğlu, Seyhan Şahan Fırat
}

Mersin Üniversitesi, Eczacılık Fakültesi, Farmakoloji Ana Bilim Dalı, Mersin

Öz

Dünya çapında, yaşa bağlı hastalıkların insidansının artmasıyla birlikte mortalite ve morbiditenin de yüksek olması yaşlanmayı yavașlatan veya geciktiren müdahalelerin geliştirilmesine neden olmaktadır. Son yıllarda yaşa bağlı gelişebilecek bozukluklarla ilgili yapılan araștırmalar mTOR sinyal ileti yolu üzerinde yoğunlaşmıştır. mTOR ve yapısına dahil olduğu kompleksler yaşlanma ile ilişkilendirilen en önemli hücresel sinyal ileti yolu molekülleri olarak kabul edilmektedir. Ayrıca, mTOR inhibitörleri ile ilgili yaşlanma sürecini yavaşlatabildiklerine dair bulguların ortaya çıkması bu konu üzerindeki ilgiyi giderek arttırmaktadır. Bu derlemede, yaşa bağlı gelişebilecek bozukluklarda mTOR sinyal ileti yolunu hedefleyen diyet türevi doğal polifenolik bileşiklerle ilgili güncel bilgiler derlenmiştir. Ayrıca, polifenollerin yaşa bağlı bozukluklarının moleküler patojenezi üzerindeki etkilerinden de bahsedilmiştir.

Anahtar Kelimeler: Yaşlanma, yaşa bağlı bozukluklar, polifenoller, mTOR

\section{Polyphenols and targets in age-related disorders; mTOR signalling pathway}

\begin{abstract}
With the increase in the incidence of age-related diseases worldwide, the high mortality and morbidity cause the development of interventions that slow down or delay aging. In recent years, studies related to age-related disorders have been focused on the mTOR signalling pathway. mTOR and the complexes that mTOR involved in its structure are considered the most important cellular signalling pathway molecules associated with aging. In addition, the emergence of evidence that mTOR inhibitors can slow down the aging process is gradually increasing interest in this issue. In this review, current knowledge about diet-derived natural polyphenolic compounds targeting mTOR signal transduction pathways has been reviewed. Also, the effects of polyphenols on the molecular pathogenesis of age-related disorders have also been discussed.
\end{abstract}

Keywords: Aging, age-related disorders, polyphenols, mTOR

Yazının geliş tarihi: 07.10.2019

Yazının kabul tarihi: 07.11.2019

Sorumlu yazar: Prof. Dr. Seyhan Şahan Fırat, Mersin Üniversitesi, Eczacılık Fakültesi, Yenişehir Kampüsü 33160 Yenişehir/Mersin, Türkiye, Tel: 032434128 15/ 12135, e-posta: seyhansahan@mersin.edu.tr

\section{Giriș}


Yaşlanma, genetik bir programla düzenlenen ve organizmayı çevresel faktörlerin de etkisiyle meydana gelen yapısal ve işlevsel değişmelerle ölüme götüren olayların toplamıdır. Son yıllarda yaşa bağlı bozuklukların tedavisi için terapötik maddelerin geliştirilmesinde önemli ilerlemeler kaydedilmiştir. Bununla birlikte, yaşlanmaya bağlı dejeneratif hastalıklar halen önemli bir ölüm nedeni olarak rol oynamaya devam etmektedir. ${ }^{1} \mathrm{Bu}$ nedenle, günümüzde yaşa bağlı dejenerasyonu yavaşlatabilen veya azaltabilen yeni tedavilerin geliştirilmesi amaçlanmaktadır.

\section{Yaşlanmanın mekanizması}

Yaşlanma, hücre ölümü riskinin artmasına veya kanser gibi hastalıkların gelişmesine neden olabilen, hücrelerin fizyolojik işlevlerinin zamana bağımlı bozulması olarak tanımlanmaktadır. ${ }^{2}$ Organizmaların strese karşı yanıt olarak adapte olmalarını engelleyen bir dizi değiştirilebilir moleküler olayları kapsayan doğal bir fenomendir. ${ }^{3}$ Temel olarak yaşlanma süreci "programlı yaşlanma" ve "aşınma ve yıpranma (wear and tear) tipi yaşlanma" olarak iki farklı başlık altında gruplandırılmaktadır. Programlı yaşlanma organizmanın içinde var olan bir kontrol mekanizmasıdır. Embriyolojik veya seksüel gelişme gibi genlerin düzenlenmesi ile ilgili süreçleri düzenlemektedir. Aşınma ve yıpranma tipi yaşlanmada ise herhangi bir kontrol mekanizması söz konusu olmamakla birlikte, çevresel etkenlerin tümü (radyasyon, kimyasal maddeler, metal iyonlar ve serbest radikaller gibi) bu süreçte etken olarak kabul edilmektedir. ${ }^{4}$

Yaşa bağlı gelişen bozukluklarda rol oynayan temel hücresel süreçler aşağıda belirtildiği gibi gruplandırılabilmektedir:

Anormal protein birikimi.

> Reaktif oksijen türlerinin birikimi ve yetersiz antioksidan savunma sistemleri.

$>$ Endoplazmik retikulum ve mitokondri gibi hücre içi organellerin strese karşı vermiş oldukları yanıtlar.
Otofaji yanitları.

$>$ Hücresel senesens.

$>$ DNA zedelenmeleri, kromatin defektleri.

Metabolik işlev bozukluğu.

Aminoasit metabolizmaları (kalori alımı, besinler, insülin duyarlılığı).

Rapamisinin memelilerdeki hedefi (mammalian target of rapamycin; mTOR)'un da dahil olduğu bazı moleküller ve kompleksler yaşlanma ile ilişkili en önemli hücresel sinyal ileti molekülleridir. ${ }^{5}$ Otofaji, hipoksiye karşı verilen yanıt, mitokondriyel solunum, mRNA translasyonu, anormal protein sentezi ve ribozom biyojenezi gibi hücresel süreçler, mTOR sinyal ileti yolunun downstream molekülleri tarafından düzenleniyor olması yaşlanma sürecinde ve yaşa bağlı moleküler ve metabolik bozukluklarda mTOR'un önemli bir rol oynadığını düşündürmektedir (Şekil 1). ${ }^{6}$

Son yıllarda yaşa bağlı dejeneratif bozukluklar ile ilgili yapılan araştırmalar mTOR sinyal ileti yolu üzerine odaklanmıștır. Giderek artan kanitlar mTOR sinyal ileti yolunun özellikle de mTOR kompleks 1 (mTORK1) aracılıklı olarak hücresel yaşlanmanın kilit düzenleyicisi olarak görev aldığını göstermektedir. ${ }^{7}$ mTOR'un kronik etkinliğinin yaşa bağlı gelişen patolojilere aracılık ettiği ve mTOR inhibisyonunun ise çeşitli canlıların (mayalardan memelilere kadar) hayvan modellerinde yaşam süresini uzattığına dair literatürde bilgiler mevcuttur. ${ }^{8}$ mTORK1'in yapısında bulunan bileșenlerin mutasyon aracılığ inhibisyonunun veya bu sinyal ileti yolunda yer alan upstream inhibitör moleküllerin etkinleșmesinin bazı organizmalarda yaşam süresini uzattığı görülmüștür. ${ }^{7}$ mTORK1 inhibitörü rapamisinin de glukoz toleransını ve insülin duyarlılığını uyararak yaşlanma süreçlerini geriletebildiği gösterilmiştir. ${ }^{9}$ Tüm bu bulgular mTOR'un inhibisyonunun yaşlanma ve yaşa bağlı bozuklukların tedavisi için inovatif bir strateji olabileceğine işaret etmektedir. 


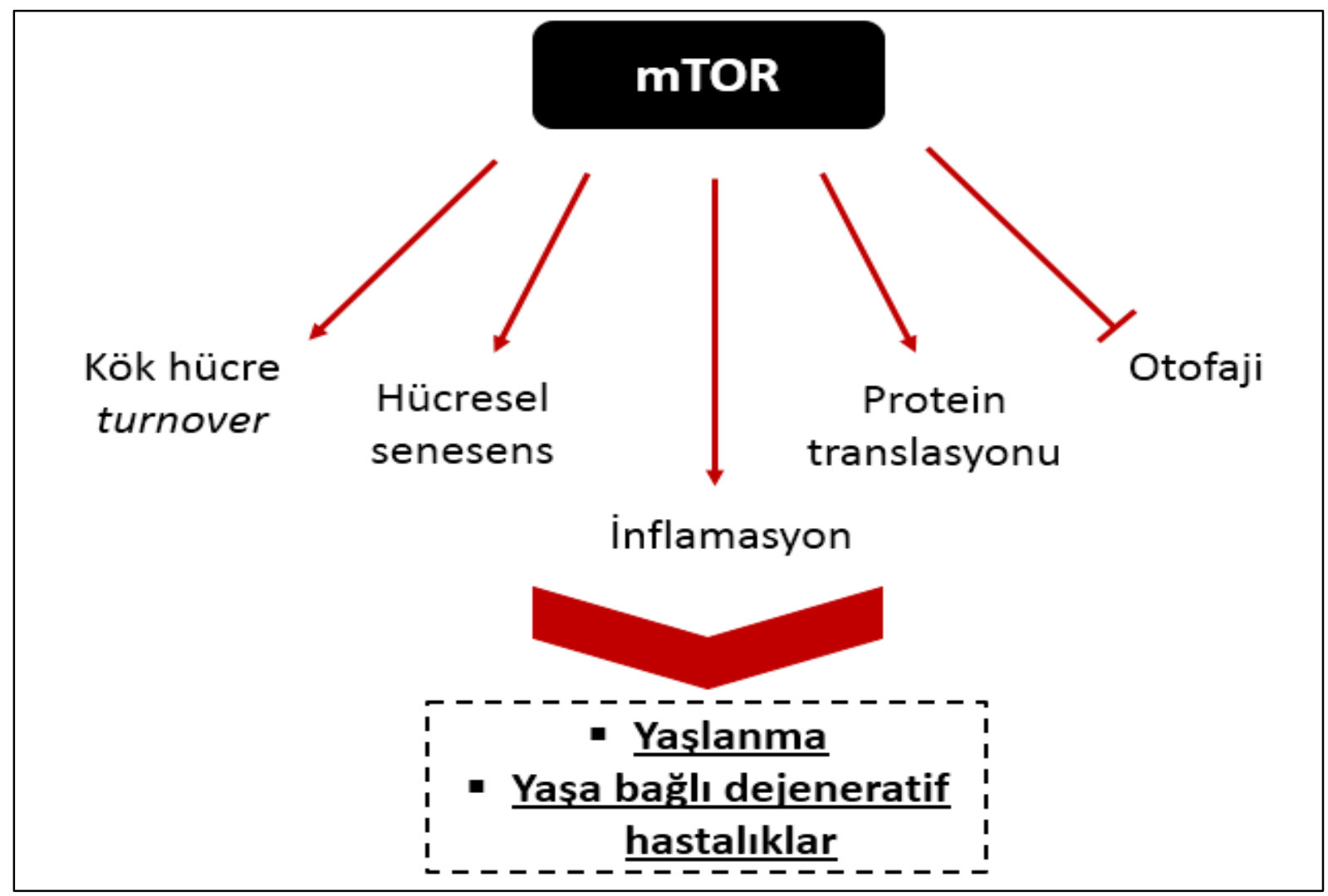

Şekil 1. Yaşlanma ve yaşa bağlı bozukluklarda mTOR’un katkısının şematik olarak gösterimi.

mTOR: Yapisl ve sinyal ileti yolu

mTOR, yapisında 2549 aminoasit içeren, N-terminal ve C-terminal ucu bulunduran bir protein kinazdır. N-terminal ucunda 20 adet birbirini izleyen Huntington, elongation factor 3 , the $A$ subunit of protein phosphatase $2 A$, and TOR1 (HEAT) tekrarları ve bunu izleyen, kinaz etkinliğini düzenlediği düşünülen, the rapamycin-associated protein [FRAP]-ataxia telangiectasia mutated [ATM]transformation/transcription domainassociated protein [TRRAP] (FAT) bölgesi yer almaktadır. C-terminal ucunda ise enzimatik etkinliğe sahip katalitik kinaz alt birimi bulunmaktadır. ${ }^{10}$

mTOR, fosfotidilinozitol-3-kinaz (phosphatidylinositol 3-kinase; PI3K) ile ilişkili protein kinazların bir üyesidir. Mayalardan memelilere kadar evrimsel olarak korunmuş olan bu enzim hücre proliferasyonu, yaşamı ve farklılaşması, hücre metabolizması ve otofaji gibi pek çok biyolojik süreçlerde düzenleyici olarak görev almaktadır. $290 \mathrm{kDa}$ ağırlığında olan bu molekül mTORK1 ve mTOR kompleks 2
(mTORK2) gibi işlevsel olarak farklı komplekslerin katalitik çekirdeğini oluşturmaktadır. $\mathrm{Bu}$ kompleksler birbirleriyle ortak ve birbirlerinden farklı protein bileşenleri içermektedirler ve farklı fizyolojik ve çevresel uyaranlara yanıt olarak çok sayıda hücresel süreçleri kontrol ederler. Ancak, mTOR'un farklı düzenleyici alt birimlere bağlanarak oluşturduğu bu komplekslerin farklı sinyal ileti yollarında yer aldığı ve inhibitörlere olan duyarlılıklarının da farklı olduğu bilinmektedir. ${ }^{10-14}$

mTORK1 mTOR, regulatoryassociated protein of mammalian target of rapamycin (Raptor), mammalian lethal with sec-13 protein 8 ( $\mathrm{mLST} 8$ ), PRAS40 ve Deptor alt birimlerinden oluşan multiprotein kompleksidir. ${ }^{10}$ PRAS40'in fosforilasyonu mTORK1 ve Raptor'un bağlanmasını önleyerek mTORK1 etkinliğini negatif yönde düzenlemektedir. Ayrica AMP ile etkinleştirilen protein kinaz (AMP-activated protein kinase; AMPK) tarafından Raptor'un fosforilasyonu da mTORK1 etkinliğini negatif yönde etkilemektedir. Rheb mTORK1'in 
upstream molekülü olup Raptor'u Ser863 konumundan fosforile etmektedir. ${ }^{14}$ Ayrica Akt, PRAS40 fosforilasyonunu inhibe ederek mTORK1'in etkinliğinin devam etmesine neden olabilmektedir. mTORK1 lipit, protein ve organellerin biyosentezleri gibi pek çok anabolik olayları uyararak, otofaji gibi katabolik olayları ise kısıtlayarak hücre büyümesi ve proliferasyonunu düzenlediği iyi bilinmektedir. ${ }^{15}$

mTORK2, mTORK1 ile ortak ve ondan farklı olan 6 protein bileşeninden olușan bir komplekstir (mTOR, Rictor, mSIN1, Protor-1, mLST8 ve Deptor ). mTORK2, mSIN1 alt birimi aracıllı̆ıyla Akt'yi etkinleștirmektedir. Ayrıca mTORK2, serum ve glukokortikoit ile uyarılan protein kinaz (serum and glucocorticoid-induced protein kinase; SGK)1/Protein kinaz C (protein kinase $C$; PKC)/Akt fosforilasyonu ile hücre iskeletinin organizasyonunu düzenlemektedir. Son yıllarda yapılan çalıșmalar, mTORK2 etkinliğinin tümör oluşumu ve fibroz gelişmesinde de önemli bir bileşen olarak görev yaptığını göstermektedir. ${ }^{16}$ mTORK1'in aksine mTORK2 sinyal ileti yolu besinlere karşı duyarsız olup PI3K sinyal iletimine ihtiyaç duyan insülin gibi büyüme faktörlerine karşı yanıt verdiği bilinmektedir.

Giderek artan bulgular, resveratrol, kurkumin, genistein, epigallokateşin gallat (EGCG) gibi fenolik yapıdaki bazı diyet türevi doğal bileșiklerin doğrudan veya dolaylı olarak mTOR etkinliğini inhibe edebileceğini göstermektedir. ${ }^{17-22}$ Diyet türevi bu doğal bileșiklerin insanlar için daha az toksik etkilerinin olabileceği de savunulmaktadır. Günümüzde, EGCG, kurkumin ve resveratrol gibi etkileri araștırılan tüm doğal ürünler, in vitro olarak oldukça yüksek seviyelerde mTOR sinyalini inhibe edebileceği gösterilmiştir. In vivo terapötik etkiler elde edebilmek için, bu doğal ürünlerin daha etkili türevlerini veya geliştirilmiş ve iyileştirilmiş farmasötik özelliklere sahip etkin formülasyonlarını geliştirmek gerekmektedir.

Polifenolik bileşiklerin hedefi: mTOR sinyal ileti yolu
Polifenoller, doğal ve sentetik formlarda bulunabilen organik kimyasal bileşiklerdir. ${ }^{23}$ Doğal polifenolik bileşikler baharatlar, çay, yağlar, renkli meyveler, üzüm çekirdeği ve kabuğu gibi günlük tüketilen gıdalarda bulunmakla birlikte serbest radikal tutucu özellikleri sayesinde potent antioksidan ve antikanser etkinlik göstermektedirler. ${ }^{24} \mathrm{Bu} \quad$ bileşiklerin süperoksit dismutaz ve katalaz gibi antioksidan enzimlerin aşırı ekspresyonunu uyardığı bilinmektedir. ${ }^{25-27}$ Ayrıca, bu bileşiklerin antioksidan özelliklerinin, yaşam süresinin uzaması ile ilişkilendirilen mTOR ve mTOR'un aracılık ettiği mekanizmalar üzerinden olabileceği savunulmaktadır (Şekil 2).

Bunlarla birlikte, polifenoller, mitokondri etkinliği ve enerji homeostazını da düzenleyebilmektedir. ${ }^{28}$ Özellikle yaşlanma sürecinde flavanoitler gibi polifenolik bileşikler oksidatif stres düzeylerinin azaltılmasında ve mitokondriyal homeostazın sürdürülmesinde önemli roller oynamaktadır. Polifenolik bileşiklerle yapilan tedavilerde oksidatif fosforilasyon ve mitokondri biyojenezinde görevli genlerin ekspresyonlarında artış olduğu da gözlenmektedir. ${ }^{29}$

Diyet türevi polifenolik bileşikler, farklı mekanizmalar üzerinden antikanser, antiinflamatuvar, antiapopitotik ve antioksidan etkinlik gibi insan sağlı̆̆ üzerinde yararlı pek çok etki göstermektedirler. Ayrıca, yaşlanma karşıtı özellikler gösteren polifenoller kronik oksidatif stres ve ürünlerinin birikimi ile ilișkili hastalıklarda yaşlanmayı önleyici bileşikler olarak değerlendirilebilmektedirler. ${ }^{30} \mathrm{Bu}$ nedenle, yaşa bağlı gelişen bozukluklarda diyet türevi polifenollerin yararlı etki potansiyellerini araştırmak son yıllarda büyük önem kazanmıștır.

Aşağıda yaşa bağlı gelişen bozukluklarda rolü olabilecek enzimlerden mTOR ve mTOR'un dahil olduğu sinyal ileti yolları üzerinde rolleri olduğu gösterilen diyet türevi polifenolik bileşiklerden bahsedilmiştir. 


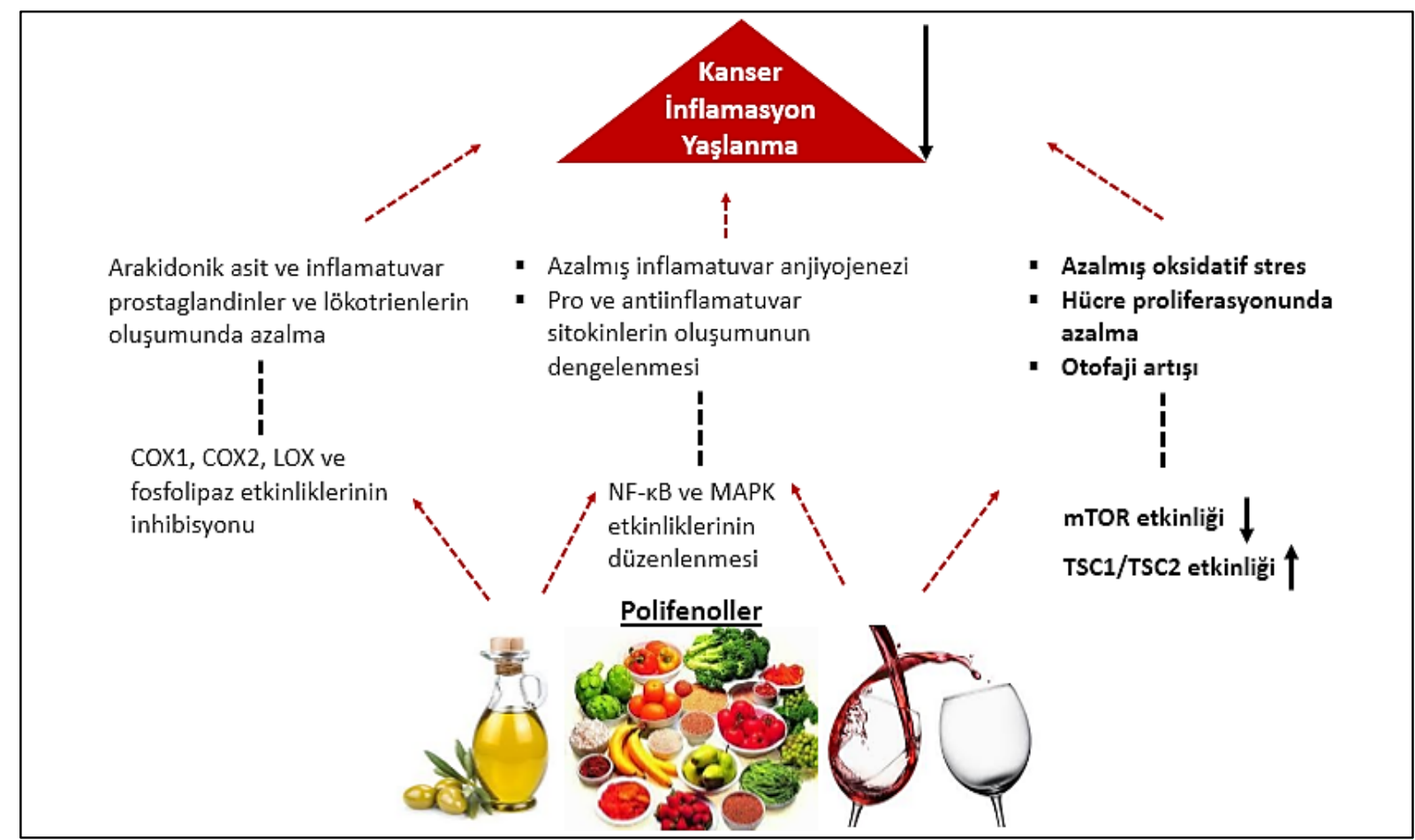

Şekil 2. Polifenollerin bazı moleküler hedefleri ve oluşturdukları etkiler. COX, siklooksijenaz; LOX, lipoksijenaz; MAPK, mitojen ile etkinleștirilen protein kinaz; mTOR, rapamisinin memelilerdeki

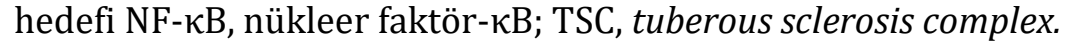

Pimentadioica berries (tüm türleri)'nin polifenolden zengin ekstresinin Akt/mTOR sinyal ileti yolu inhibisyonuna neden olmakta ve bu etkisiyle otofaji etkinliğini arttırarak yaşa bağlı gelişen dejenerasyonlarda antiproliferatif etkinlik göstermektedir. $\mathrm{Bu}$ bileşiklerin MCF7 hücrelerinde, Akt ve mTOR fosforilasyonunu azaltarak, otofaji ile ilgili genlerin ekspresyonunu arttırdığı gösterilmiştir. ${ }^{31}$

PI3K/Akt/mTOR sinyal ileti yolunu düzenleyerek hücresel otofajik yanıtları uyarabildiği bilinmektedir. Honokiol uygulaması, özellikle nöroblastoma hücrelerinde PI3K ve Akt etkinliklerini azaltarak mTOR fosforilasyonunu baskılamaktadır. mTOR etkinliğinin baskılanmasının da ULK1 ve otofaji ile ilişkili gen (autophagy-related genes; ATG)13 gibi downstream protein kinazları uyararak otofajik yanıtları arttırdığı gösterilmiştir. ${ }^{32}$

Üzerinde en çok çalışılan ve en iyi bilinen doğal polifenolik bileşiklerden birisi de resveratroldur. Resveratrol $(3,40,5$ trihidroksi-trans-stilben) bitkilerin kökleri ile dut ve üzüm gibi yenilebilir meyvelerde bulunan polifenolden zengin doğal bir bileşiktir. Resveratrol uygulamasının, uygulanan hücre ve organizmalarda inflamasyonu azaltması ve tümör hücrelerinin ölümünü uyarması gibi bazı yararlı etkilerinin bulunduğu gösterilmiştir. ${ }^{33}$ Aynı zamanda, resveratrolun yaşlanma karşıtı etkilerinin olduğu da bildirilmiştir. Bu etkilerin 2 farklı mekanizma ile gerçekleştirebileceği açıklanmıştır: 1) İnsülin benzeri büyüme faktörü (IGF)-1'i baskllayarak ve PI3K/Akt/mTOR sinyal ileti yolu aracılığıyla insülin duyarlılığını arttırarak ve 2) AMPK ve Sirtuin (Sirt) 1 proteinlerinin etkinliklerini uyararak. Sirt1, AMPK'nin pozitif düzenleyicisi olarak rol almakta ve mTOR etkinliğini inhibe etmektedir. AMPK'nin etkinleşmesi mTOR etkinliğini baskılamakta ve dejeneratif olayların başlamasını geciktirmektedir. Aynı zamanda, resveratrol peroksizom proliferatörü ile etkinleştirilen reseptör-c ko-aktivatör 1a (PPAR-co-1a) etkinliğini de arttırabilmektedir.34-36 Resveratrol PI3K/Akt yolu inhibisyonu, PTEN ekspresyonunun uyarılması, AMPKtuberous sclerosis complex (TSC) $1 / 2$ etkinliğinde artma ve DEPTOR-mTOR 
etkileșiminin uyarılması ile mTOR inhibitörü etkileri gösterebileceği son yıllarda yapılan çalışmalarla gösterilmiştir. ${ }^{37-38}$

Apigenin, meyvelerde (portakal, elma, dut ve üzüm gibi), sebzelerde (soğan, domates, maydanoz, kereviz, brokoli, tatl yeşilbiber, arpa) ve içkilerde bolca bulunan bir flavonoit türüdür. Tong ve ark., son yıllarda apigeninin PI3K/Akt/mTOR sinyal ileti yolunun inhibisyonu aracılığıyla antiproliferatif etkilerinin olabileceğini göstermişlerdir. ${ }^{39}$ Apigeninin bu etkisinin doğrudan PI3K/Akt yolu etkinliğini baskılayarak veya dolaylı olarak AMPK-TSC aksını etkinleştirerek gerçekleştirebileceğini gösteren bulgular da bulunmaktadır. ${ }^{37}$

Flavonoit grubu fenolik bileşiklerin bir başka üyesi olan fisetin ise elma, çilek, hurma ve soğan gibi meyve ve sebzelerde bulunmaktadır. Yapılan in vivo ve in vitro çalışmalarda fisetinin farklı kanser hücrelerinde hücre proliferasyonunu inhibe ederek ve hücre ölümünü uyararak potansiyel antikanser etkilerinin olduğu gösterilmiștir. Epidemiyolojik ve klinik çalışmalar fisetinin çok sayıda hedef molekülünün olduğunu göstermektedir.40 Son yıllarda yapılan çalışmalardan elde edilen bulgular fisetinin antikanser etkinliğinin PI3K/Akt ve mTOR sinyal ileti yollarının inhibisyonu ile bağlantılı olduğunu göstermektedir. ${ }^{41}$ Fisetin Raptor, Rictor, PRAS40 ve mLST8 ekspresyonunu baskılamakta ve devaminda mTORK1 ve mTORK2 oluşumunu azaltmaktadır. Aynı zamanda, fisetin S6K1, eukaryotic translation initiation factor $4 E$ (eIF4E) ve eIF4E binding protein 1 (4EBP1), gibi mTOR'un downstream moleküllerinin ekspresyonlarını da inhibe etmektedir. Dahası, fisetin PI3K'nin düzenleyici (p85) ve katalitik (p110) alt birimlerinin ekspresyonunu azaltmakta, AMPK etkinliğini arttırmakla birlikte Akt ve mTOR fosforilasyonunu azaltmaktadır. Bunların yanı sıra, yapılan çalışmaların sonuçlarına göre fisetin, kombinasyon halinde uygulandığında birlikte kullanıldığ kemoterapötik ilaçların sitotoksik etkilerini arttırabilmektedir.42

Bir diğer flavonoit türevi fenolik bileşik ise soya ve soya ürünleri ile kuru baklagillerde bolca bulunan izoflavonlardır. İzoflavonların antioksidan, antiproliferatif, antikanser, antianjiyojenik ve antiinflamatuvar özellikler gösterebildikleri iyi bilinmektedir. Antiproliferatif etkilerinin yanında birlikte uygulanan radyoterapi ve kemoterapinin etkinliklerini arttırabilmektedirler. İzoflavonlar içerisinde üzerinde en çok çalışanları genistein ve deguelindir. Özellikle genistein mesane kanseri ile ilgili klinik çalışmalarda faz II aşamasındadır. PI3K/Akt/mTOR gibi pek çok sinyal ileti yolu izoflavonların hedefi olarak tanımlanmıştır. ${ }^{43}$

Kurkumin, Asya ülkelerinde yaygın olarak kullanılan bir baharatın bileşiminde bulunan ve zerdeçal (Curcuma longa) bitkisinin rizomlarından (Rhizoma Curcumae) elde edilen major polifenolik biyoaktif bileşenlerin en önemlisidir ve yeni antikanser molekül olarak klinik çalışmalarda denemeleri devam etmektedir. Ancak, antikanser etki mekanizması henüz tam olarak aydınlatılamamıştır. Kurkuminin hücre siklusu, apopitoz, proliferasyon, sağ kalım, yeni kan damarlarının oluşumu, metastaz, inflamasyon ve bu olaylarda rol oynayan çok sayıda hücre sinyal ileti yollarını etkileyerek etki gösterdiği düşünülmektedir. ${ }^{44}$ Kurkuminin çok sayıda hücresel hedef moleküllerinin ortaya atılmasına rağmen bu hedeflerin hiçbirinin kurkuminin birincil hedefi olmadığ gösterilmiştir. Son yıllarda yapılan çalışmalarda, kurkuminin, birincil hedef olarak Akt/mTOR ve AMPK/mTORK1 sinyal ileti yolları üzerindeki etkisi nedeniyle antikanser etkiler gösterebileceği üzerinde durulmaktadır. ${ }^{45}$ Kurkumin, çok sayıda kanser hücre dizisinde, yüksek derişimlerde (> $40 \mu \mathrm{M}$ ) mTORK2 substratı olan Akt fosforilasyonunu inhibe ederken düșük derişimlerde $\quad\left(<\begin{array}{ccc}40 & \mu \mathrm{M}) & \text { mTORK1'in }\end{array}\right.$ downstream molekülleri olan S6K1 ve 4EBP1 fosforilasyonunu inhibe etmektedir. Kurkumin ile Akt/mTOR sinyal ileti yolu inhibisyonu, mTOR-Raptor kompleksinin bozulması ve protein fosfataz 2A'nın etkinleşmesi sonucu ortaya çıkmaktadır. ${ }^{37}$ Ayrica, kurkumin PI3K/Akt/mTOR yolu aracılığıyla insülin/IGF aracılığıyla başlatılan sinyal ileti yolu etkinliğini baskılamakta, hücresel senesensi geciktirebilmektedir. ${ }^{46}$ Aynı zamanda, bu bileşikler, doğrudan da mTOR kinazl inhibe edebilmektedir. ${ }^{47}$ mTORK1 ile Raptor, mTORK2 ile Rictor 
arasındaki etkileşimi bozabilirler. ${ }^{48}$ Kurkuminin antikanser etkinliğe sahip olması, molekül ağırlığının düşük olması ve toksisitesinin düşük olması, bu molekülü; potansiyel kemoterapötik ilaçların geliştirilmesinde ideal molekül haline getirmektedir. Kurkuminin kimyasal yapısından yola çıkarak çeşitli analogları sentezlenmekte ve antikanser etkileri denenmektedir.

Kuersetin, günlük diyette temel olarak tüketilen özellikle çay, soğan, kırmızı üzüm ve elma gibi besinlerde bulunan polifenolik bir bileşiktir. Kuersetinin özellikle kanser, kardiyovasküler hastalıklar, inflamatuvar ve dejeneratif hastalıkların semptomlarını iyileștirmesindeki rolü üzerine yoğunlaşılmıştır. ${ }^{49-50}$ Honokiol, kurkumin ve diğer polifenoller gibi kuersetin de antioksidan, antiinflamatuvar, antiamiloidojenik etkiler sergilemektedir. Dahası, nörodejenerasyon, kanser ve vasküler hastalıklara karşı koruyucu rol oynayan otofajik yanitları da düzenlemektedir. Kuersetin, Notch 1 ekspresyonunu inhibe etmekte ve devaminda downstream protein kinazlar olan Akt ve mTOR'un fosforilasyonlarını da baskllamaktadır ve apopitozu uyarmaktadır. ${ }^{51}$ Son yıllarda konu ile ilgili yapılan çalışmaların sonuçları, kuersetin ve diğer polifenollerin yaşlanma hücrelerini yok etmede ve yaşam ömrünün uzamasını arttırmadaki önemini vurgulamaktadır. Bu bilgilerin yanı sıra, uygun olmayan biyoyararlanım ve farmakokinetik özellikleri nedeniyle kuersetinin kanser tedavisinde kullanılabilmesi için yeni formülasyonları veya kimyasal modifikasyonlarının yapılması gerekmektedir. ${ }^{37}$

Pek çok çalışma ile farklı deneysel modellerde senesens ve yaşlanmayla ilişkili olaylara karşı otofajik yanıtlar aracılığıyla yararlı etkileri gösterilen oleuropein, zeytin ve zeytinyağında bulunan temel polifenolik moleküldür.52 Benzer șekilde, oleuropein, yaşlanmayla ilişkili bozuklukların oluşmasını ve gelişmesini $\mathrm{Ca}^{+2} / \mathrm{CaMKK} \beta / \mathrm{AMPK} / \mathrm{mTOR}$ yolu aracılığıyla önlemektedir. Oleuropein uygulanması hücre içi depolardan $\mathrm{Ca}^{+2}$ salıverilmesine yol açmaktadır ve açığa çıkan serbest $\mathrm{Ca}^{+2}$ AMPK'nin upstream molekülü olan CaMKK $\beta^{\prime} y$ etkinleştirmektedir.
CaMKK $\beta$, AMPK'yi etkinleștirerek mTOR etkinliğinin baskılanmasına ve otofajik yanitlarin uyarılmasina neden olabilmektedir. ${ }^{53}$

İndol ise brokoli, lahana, karnıbahar ve brüksel lahanası gibi sebzelerin dahil olduğu turpgiller ailesine ait sebzelerde bulunan doğal bileșiklerdir. İndol türevi bileşiklerden indol-3-karbinol (I3C) ve onun in vivo oluşan ürünü 3-3-diindolmetan (DIM) antikanser özellikleri olan potent bileşiklerdir. İndol türevi bileşiklerin etki mekanizmalarının araştırıldığı çalışmalarda I3C, DIM ve türevlerinin PI3K/Akt/mTOR yolunu ve downstream molekül olan NF- $\kappa B^{\prime} y i$ inhibe edebildikleri anlaşılmıștır. $\mathrm{Bu}$ mekanizmalar ile kanser hücrelerinin invazyonu, anjiyojenezi ve ilaçlara karşı direnç gelişimini inhibe edici etkileri açıklanabilmektedir. ${ }^{54}$

Epigallokateşin-3-gallat (EGCG) yeşil çayda bulunan ve üzerinde en çok çalışılan bir diğer polifenol türevi bileşiktir. Antioksidan etkisi üzerine yapılan çok sayıda çalışmanın yanı sıra son yıllarda antikanser etkinliği de vurgulanmaktadır. Çeşitli kanser tiplerinde apopitotik, antineoplastik, antimetastatik özellik gösterdiği belirlenmiş ve bu özellikleri düzenleyen genetik ve epigenetik mekanizmalar aydınlatılmaya başlanmıştır. ${ }^{55}$ Keloit fibroblastlar ve HMC-1 hücrelerine uygulanan EGCG doza bağımlı olarak Akt, S6K ve 4EBP1 fosforilasyonların azalttığı gösterilmiştir.56 p53 pozitif ve negatif insan hepatoma hücrelerinde EGCG uygulamasının, AMPK etkinliğinin artmasına ve ardından downstream moleküller olan mTOR ve 4EBP1'in baskılanmasina ve genel olarak mRNA translasyonunun azalmasına yol açtığı bildirilmiştir. ${ }^{57}$ Özellikle kanser, kardiyovasküler ve nörolojik hastalıklarda umut vaat eden terapötik potansiyelleri nedeniyle yeşil çay ve kateşinlerin çok farklı farmakolojik etkileri bildirilmiştir. ${ }^{58}$

\section{Sonuç}

Son yıllarda, yaşlanma ve yaşa bağlı bozukluklara neden olan moleküler ve hücresel olaylar hakkındaki bilgiler oldukça artmıştır. Bu konudaki bilgi ve birikimin giderek artmasının, yaşlanma ve yaşa bağlı hastalıkların yavaşlatılması veya 
geciktirilmesine yönelik hedeflerin geliştirilmesine neden olması beklenmektedir. Hızla büyüyen ve yaşlanan nüfusun artan sosyal ve ekonomik yükü göz önüne alındığında, yakın gelecekte mTOR inhibitörleri için ilave terapötik kullanımların belirlenmesi söz konusu olabilecektir. mTOR ve ilgili sinyal ileti yollarını hedefleyerek yaşlanma sürecini geciktirebileceği, yaşam ömrünü uzatabileceği ve yaşa bağlı dejenerasyonu ve ilişkili morbidite ve mortaliteyi azaltabileceği için polifenolik bileşikler üzerindeki araştırmalar giderek artan oranda devam edecektir.

\section{Kaynaklar}

1. Minino AM, Murphy SL. Death in the United States, 2010. NCHS Data Brief 2012;99:1-8.

2. Zoncu R, Efeyan A, Sabatini DM. mTOR: from growth signal integration tocancer, diabetes and ageing. Nat Rev Mol Cell Biol 2011;12(1):21-35.

3. Kyriakakis E, Princz A, Tavernarakis N. Stress responses during ageing:molecular pathways regulating protein homeostasis. Stress Responses Methods Protoc 2015;1292:215-234.

4. Mondal SC, Singh P, Kumar B, Singh SK, Gupta SK, Verma A. Ageing and potential anti-aging phytochemicals: an overview. World J Pharm Pharm Sci 2014;4:426-454.

5. Zhang Y. Ageing and cancer: breaking the don't put all eggs in one basketand natural self-organisation, and their potential reprogramming viamodulation of $\mathrm{mi}$ 2/NuRD, mTOR kinase and metabolism. Enz Eng 2012;2:109.

6. McCormick MA, Tsai SY, Kennedy BK. TOR and ageing: a complex pathway for a complex process. Philos Trans $R$ Soc Lond B Biol Sci 2011;366(1561):17-27.

7. Johnson SC, Rabinovitch PS, Kaeberlein M. mTOR is a key modulator ofageing and age-related disease. Nature 2013;493(7432):338-345.

8. Bjedov I, Toivonen JM, Kerr F, Slack C, Jacobson J, Foley A, Partridge L. Mechanisms of life span extension by rapamycin in the fruit fly Drosophila melanogaster. Cell Metab 2010;11:35-46.
9. Schreiber KH, Ortiz D, Academia EC, Anies AC, Liao CY, Kennedy BK. Rapamycinmediated mTORC2 inhibition is determined by the relative expression of FK506-binding proteins. Aging cell 2015;14(2):265-273.

10 Laplante M, Sabatini DM. mTOR signaling at a glance. J Cell Sci 2009;122(20): 35893594 .

11. Alessi DR, Pearce LR, Garcia-Martinez JM. New insights into mTOR signaling: mTORC2 and beyond. Sci Signal 2009;2(67):27.

12. Hara K, Maruki $Y$, Long $X$, Yoshino K, Oshiro N, Hidayat S, Tokunaga C, Avruch J, Yonezawa K. Raptor, a binding partner of target of rapamycin (TOR), mediates TOR action. Cell 2002;110(2):177-189.

13. Sarbassov DD, Ali SM, Kim DH, Guertin DA, Latek RR, Erdjument-Bromage $\mathrm{H}$, Tempst P, Sabatini DM. Rictor, a novel binding partner of mTOR, defines a rapamycin-insensitive and raptorindependent pathway that regulates the cytoskeleton. Curr Biol 2004;14(14):1296-1302.

14. Dibble CC, Cantley LC. Regulation of mTORC1 by PI3K signaling. Trends Cell Biol 2015;25(9):545-555.

15. Peterson TR, Laplante M, Thoreen CC, Sancak Y, Kang SA, Kuehl WM, Gray NS, Sabatini DM. DEPTOR is an mTOR inhibitor frequently overeexpressed in multiple myeloma cells and required for their survival. Cell 2009;137(5):873-886.

16. Carr TD, Feehan RP, Hall MN, Rüegg MA, Shantz LM. Conditional disruption of rictor demonstrates a direct requirement for mTORC2 in skin tumor development and continued growth of established tumors. Carcinogenesis 2015;36(4):487497.

17. Beevers CS, Chen L, Liu L, Luo Y, Webster NJ, Huang S. Curcumin disrupts the Mammalian target of rapamycinraptor complex. Cancer Res 2009;69:1000-1008.

18. Jiang $\mathrm{H}$, Shang $\mathrm{X}, \mathrm{Wu} \mathrm{H}$, Gautam SC, AlHolou S, Li C, Kuo J, Zhang L, Chopp M. Resveratrol downregulates PI3K/Akt/mTOR signaling pathways in human U251 glioma cells. J Exp Ther Oncol 2009;8:25-33. 
19. Zhang Q, Kelly AP, Wang L, French SW, Tang X, Duong HS, Messadi DV, Le AD. Green tea extract and (-)epigallocatechin-3-gallate inhibit mast cell-stimulated type I collagen expression in keloid fibroblasts via blocking PI3K/AkT signaling pathways. J Invest Dermatol 2006;126:2607-2613.

20. Anastasius N, Boston S, Lacey M, Storing N, Whitehead SA. Evidence that low-dose, long-term genistein treatment inhibits oestradiol-stimulated growth in MCF-7 cells by down-regulation of the PI3-kinase/Akt signalling pathway. $J$ Steroid Biochem Mol Biol 2009;116:50-55.

21. Nakamura Y, Yogosawa S, Izutani $Y$, Watanabe H, Otsuji E, Sakai T. A combination of indol-3-carbinol and genistein synergistically induces apoptosis in human colon cancer HT-29 cells by inhibiting Akt phosphorylation and progression of autophagy. Mol Cancer 2009;8:100.

22. Kong D, Banerjee S, Huang W, Li Y, Wang Z, Kim HR, Sarkar FH. Mammalian target of rapamycin repression by $3,3^{\prime}$ diindolylmethane inhibits invasion and angiogenesis in platelet-derived growth factor-D-overexpressing PC3 cells. Cancer Res 2008;68:1927-1934.

23. Lu W, Kelly AL, Miao S. Emulsion-based encapsulation and deliverysystems for polyphenols. Trends Food Sci Technol. 2016;47:1-9.

24. Sharma RA, Gescher AJ, Steward WP. Curcumin: the story so far. Eur J Cancer, 2005;41:1955-1968.

25. Alanon M, Castro-Vazquez L, DiazMaroto M, Gordon M, Perez-Coello M. A study of the antioxidant capacity of oak wood used in wine ageing andthe correlation with polyphenol composition. Food Chem 2011;128(4):997-1002.

26. Schaffer S, Asseburg H, Kuntz S, Muller WE, Eckert GP. Effects ofpolyphenols on brain ageing and Alzheimer's disease: focus on mitochondria. Mol Neurobiol 2012;46(1):161-178.

27. Shen Y, Zhang H, Cheng L, Wang L, Qian $\mathrm{H}, \mathrm{Qi} X$. In vitro and in vivo antioxidant activity of polyphenols extracted from black highland barley. Food Chem 2016;194:1003-1012.
28. Lagouge M, Argmann C, Gerhart-Hines $\mathrm{Z}$, Meziane $\mathrm{H}$, Lerin $\mathrm{C}$, Daussin $\mathrm{F}$, Messadeq N, Milne J, Lambert P, Elliott P. Resveratrol improves mitochondrial function and protects against metabolic disease by activating SIRT1 and PGC-1. Cell 2006;127(6):1109-1122.

29. Charles AL, Meyer A, Dal-Ros S, Auger C, Keller N, Ramamoorthy TG, Zoll J, Metzger D, Schini-Kerth V, Geny B. Polyphenols preventageing-related impairment in skeletal muscle mitochondrial function through decreased reactive oxygen species production. Exp Physiol 2013;98(2):536545.

30. Khurana $S$, Venkataraman $K$, Hollingsworth A, Piche M, Tai T. Polyphenols: benefits to the cardiovascular system in health and in aging. Nutrients 2013;5(10):3779-3827.

31. Zhang L, Shamaladevi N, Jayaprakasha G, Patil B, Lokeshwar B. Polyphenol-rich extract of Pimenta dioica berries (Allspice) kills breast cancercells by autophagy and delays growth of triple negative breast cancer inathymic mice. Oncotarget 2015;6(18):16379-16395.

32. Yeh PS, Wang W, Chang YA, Lin CJ, Wang JJ, Chen RM. Honokiol induces autophagy of neuroblastoma cells through activating thePI3K/Akt/mTOR and endoplasmic reticular stress/ERK1/2 signaling pathways and suppressing cell migration. Cancer Lett 2016;370(1):6677.

33. Chung JH, Manganiello V, Dyck JR. Resveratrol as a calorie restriction mimetic: therapeutic implications. Trends Cell Biol 2012;22:546-554.

34. Park SJ, Ahmad F, Philp A, Baar K, Williams $\mathrm{T}$, Luo $\mathrm{H}, \mathrm{Ke} \mathrm{H}$, Rehmann $\mathrm{H}$, Taussig R, Brown AL, Kim MK, Beaven MA, Burgin $\mathrm{AB}$, Manganiello $\mathrm{V}$, Chung $\mathrm{JH}$. Resveratrol ameliorates aging-related metabolic phenotypesby inhibiting cAMP phosphodiesterases. Cell 2012;148(3):421-433.

35. Morselli E, Maiuri MC, Markaki M, Megalou E, Pasparaki A, Palikaras K, Criollo A, Galluzzi L, Malik SA, Vitale I. The life span-prolongingeffect of sirtuin-1 is 
mediated by autophagy. Autophagy 2010;6(1):186-188.

36. Barger JL, Kayo T, Vann JM, Arias EB, Wang J, Hacker TA, Wang Y, Raederstorff D, Morrow JD, Leeuwenburgh C. A low dose of dietary resveratrol partially mimics caloric restriction and retards aging parameters in mice. PLoS One 2008;3(6):2264.

37. Huang S. Inhibition of PI3K/Akt/mTOR signaling by natural products. 2013. Anticancer Agents Med Chem 2013;13(7):967-970.

38. Liu M, Wilk SA, Wang A, Zhou L, Wang RH, Ogawa W, Deng C, Dong LQ, Liu F. Resveratrol inhibits mTOR signaling by promoting the interaction between mTOR and DEPTOR. $J$ Biol Chem 2010;285:36387-36394.

39. Tong $\mathrm{X}$, Pelling J. Targeting the PI3K/Akt/mTOR axis by apigenin for cancer prevention. Anticancer Agents Med Chem 2013;13(7):971-978.

40. George VC. Promising tumor inhibiting potentials of fisetin throughPI3K/AKT/mTOR pathway. Am J Transl Res 2016;8(2):1293-1294.

41. Syed DN, Adhami VM, Khan MI, Mukhtar H. Inhibition of Akt/mTOR signaling by the dietary flavonoid fisetin. Anticancer Agents Med Chem 2013;13(7):995-1001.

42. Haddad AQ, Fleshner N, Nelson C, Saour B, Musquera M, Venkateswaran V, Klotz L. Antiproliferative mechanisms of the flavonoids2,2'-Dihydroxychalcone and fisetin in human prostate cancer cells. Nutr Cancer 2010;62(5):668-681.

43. Ahmad A, Biersack B, Li Y, Bao B, Kong D, Schobert R, Padhye SB, Sarkar FH. Deregulation of PI3K/Akt/mTOR signaling by isoflavones and its implication in cancer research. Anticancer Agents Med Chem 2013;13(7):1014-1024.

44. Anand $P$, Sundaram C, Jhurani S, Kunnumakkara AB, Aggarwal BB. Curcumin and cancer: An "old-age" disease with an "age-old" solution. Cancer Letters 2008;267:133-164.
45. Beevers CS, Huang S. Hitting the Golden TORget: Curcumin's Effects on mTOR Signaling. Anticancer Agents Med Chem 2013;13(7):988-994.

46. Brown D. Antibiotic resistance breakers: can repurposed drugs fill theantibiotic discovery void? Nature Rev Drug Discovery 2015;14(12):821-832.

47. Wee LH, Morad NA, Aan GJ, Makpol S, Ngah WZW, Yusof YAM. Mechanism of chemoprevention against colon cancer cells using combinedgelam honey and ginger extract via mTOR and Wnt/ $\beta$ catenin pathways. Asian Pacific J Cancer Prev 2015;16(15):6549-6456.

48. Cerella C, Gaigneaux A, Dicato $M$, Diederich $\mathrm{M}$, Antagonistic role ofnatural compounds in mTOR-mediated metabolic reprogramming. Cancer Lett 2015;356(2):251-262.

49. Hoek-van den Hil EF, van Schothorst EM, van der Stelt I, Swarts HJ, van Vliet M, Amolo T, Vervoort JJ, Venema D, Hollman PC, Rietjens IM, Keijer J. Direct comparison of metabolic health effects of the flavonoids quercetin, hesperetin, epicatechin, apigenin and anthocyanins inhigh-fat-diet-fed mice. Genes Nutr 2015;4:469.

50. Kobylinska A, Janas KM. Healthpromoting effect of quercetin in human diet. Postepy Hig Med Dosw 2015;69:5162.

51. Chen X, Dong XS, Gao HY, Jiang YF, Jin YL, Chang YY, Chen LY, Wang JH. Suppression of HSP27 increases the antitumor effects of quercetin inhuman leukemia U937 cells. Mol Med Rep 2016;13(1):689-696.

52. Hadrich F, Garcia M, Maalej A, Moldes M, Isoda H, Feve B, Sayadi S. Oleuropein activated AMPK and induced insulin sensitivity in C2C12 muscle cells. Life Sci 2016;151:167-173.

53. Rigacci S, Miceli C, Nediani C, Berti A, Cascella R, Pantano D, Nardiello P, Luccarini I, Casamenti F, Stefani M. Oleuropein aglycone induces autophagy via the AMPK/mTOR signalling pathway: 
a mechanistic insight. Oncotarget 2015;6(34):35344-35357.

54. Ahmad A, Biersack B, Li Y, Kong D, Bao B, Schobert R, Padhye SB, Sarkar FH. Targeted regulation of PI3K/Akt/mTOR/NF- $\kappa \mathrm{B}$ signaling by indole compounds and their derivatives: Mechanistic details and biological implications for cancer therapy. Anticancer Agents Med Chem 2013;13(7):1002-1013.

55. Singh BN, Shankar S, Srivastava RK. Green tea catechin, epigallocatechin-3gallate (EGCG): mechanisms, perspectives and clinical applications. Biochem Pharmacol 2011;82:1807-1821.

56. Zhang Q, Kelly AP, Wang L, French SW, Tang X, Duong HS, Messadi DV, Le AD. Green tea extract and (-)epigallocatechin-3-gallate inhibit mast cell-stimulated type I collagen expression in keloid fibroblasts via blocking PI3K/Akt signaling pathways. J Invest Dermatol 2006;126:2607-2613.

57. Huang $\mathrm{CH}$, Tsai SJ, Wang YJ, Pan $\mathrm{MH}$, Kao JY, Way TD. EGCG inhibits protein synthesis, lipogenesis, and cell cycle progression through activation of AMPK in p53 positive and negative human hepatoma cells. Mol Nutr Food Res 2009;53:1156-1165.

58. Zaveri NT. Grean tea and its Polyphenolic catechins: medicinal uses in cancer and noncancer applications. Life Sci 2006;78:2073-2080. 